\title{
The Stochastic Evolution Game of Knowledge Sharing in the Infrastructure PPP Supply Chain Network
}

\author{
Huimin Li $\mathbb{D},{ }^{1,2}$ Fuqiang Wang, ${ }^{1,3}$ Lunyan Wang $\mathbb{D}^{1,4}{ }^{1,4}$ Limin $\mathrm{Su}^{5}$ and Chengyi Zhang ${ }^{6}$ \\ ${ }^{1}$ Department of Construction Engineering and Management, North China University of Water Resources and Electric Power, \\ Zhengzhou 450045, China \\ ${ }^{2}$ School of Architecture and Built Environment, Centre for Asian and Middle Eastern Architecture, University of Adelaide, \\ Adelaide 5005, Australia \\ ${ }^{3}$ Henan Key Laboratory of Water Environment Simulation and Treatment, Zhengzhou 450045, China \\ ${ }^{4}$ Environment Governance and Ecological Restoration Academician Workstation of Henan Province, Zhengzhou 450002, China \\ ${ }^{5}$ School of Mathematics and Statistics, North China University of Water Resources and Electric Power, Zhengzhou 450045, China \\ ${ }^{6}$ Department of Civil and Architectural Engineering, University of Wyoming, Laramie, WY 82071, USA
}

Correspondence should be addressed to Lunyan Wang; wanglunyan@ncwu.edu.cn

Received 13 September 2020; Revised 30 September 2020; Accepted 4 October 2020; Published 24 October 2020

Academic Editor: Guangdong Wu

Copyright $\odot 2020$ Huimin Li et al. This is an open access article distributed under the Creative Commons Attribution License, which permits unrestricted use, distribution, and reproduction in any medium, provided the original work is properly cited.

\begin{abstract}
Due to the complexity and randomness of environmental change, the knowledge-sharing behavior of members in the PPP supply chain will be affected by random disturbance factors. Traditional evolutionary game models cannot describe this effect. In this study, Gaussian white noise is introduced into the stochastic evolutionary game model of PPP supply chain knowledge sharing. The numerical simulation of the model is carried out to analyze the influence of parameter changes on the strategy selection of enterprise groups. The result shows that the strong knowledge power enterprise group is more sensitive with the variation of parameters than that of the weak knowledge power enterprise group. However, the weak enterprise group has a more vital willingness to share knowledge. Incentive measures can increase the knowledge-sharing benefits and promote the strong knowledge powerful enterprise group toward the sharing strategy. Increasing the mutual trust coefficient, reducing the sharing cost, and improving the enterprise's transformation ability will help both sides to evolve into the sharing strategy more quickly. This study would have significance for PPP project performance and industry innovation.
\end{abstract}

\section{Introduction}

Compared with the traditional project delivery system in which the government provides public infrastructures and goods only, the public-private partnership (PPP) is a powerful mode to alleviate the financial pressure of the government and provide professional and high-quality services for the public. PPP has been thriving in the fields of municipal facilities, transportation, medical care, and pension in recent years. PPP is a partnership for design, construction, operation and maintenance, and service delivery of public projects by the private sector, which is selected by the government through the public procurement procedure. It is a nexus of contracts among various participants where the relationships are established through contractual agreements between financers, designers, government, contractors, operators, and customers. Raising funds, constructing buildings, and servicing the public are dependent on the well-established financial and legal structure of PPP [1]. It is believed that the legal and financial structure of PPP agreements is best positioned in close proximity to network analysis.

Construction products and services are delivered by the supply chain. A construction supply chain involves all of the partner organizations involved in the delivery of the infrastructure asset to the client. According to Christopher [2], a supply chain is the network of team organizations that are involved through downstream and upstream linkages in different activities and processes that produce products and services in the hands of the ultimate consumer. These 
organizations in the construction supply chain are engaged in downstream and upstream flows of finances, services, information, and products, from the manufacturer to the main contractor, supplier, subcontractor, client, and to the construction end-user, and the building occupant [3]. A supply chain of PPP projects is the construction supply chain integration in the PPP network. The supply chain of the PPP project broadens the chain of the construction supply chain, from financing, design, construction, operation and maintenance, and service delivery, which is the life cycle of a project.

Knowledge-sharing behavior would improve multiknowledge integration, which may transform knowledge resources into knowledge capital and increase knowledge incrementally, to improve the overall production performance of the construction industry [4]. With the development of more cooperative, long-term relationships between clients, contractors, and subcontractors, they become more conducive to the spread of knowledge, learning, and innovation [5]. Such initiatives promise not only improvements in the project performance but also more excellent responsiveness to client needs and improved innovation potential [6]. Knowledge management plays an essential role in improving governance by developing processes and tools, the acceleration of learning to improve the decision-making ability of actors in PPP projects [7].

There are some difficulties with the PPP supply chain for knowledge sharing. Firstly, knowledge in the construction industry includes finance, design, architecture, planning, surveying, construction, and operation service. The construction sector could be considered as a knowledge-intensive sector because the knowledge is characterized by a high degree of tacit knowledge but not codified knowledge as in the manufacturing sector [7]. Secondly, professional knowledge is deeply embedded in a mutualization process, where the participant with each other produces their final output. Finally, the partners in the PPP supply chain are driven by different objectives and value systems. There could be some tension relationship between the private sector motivated by profit maximization and the public sector to deliver an acceptable level of service for the public good in a manner that represents value for money [7].

Knowledge sharing among supply chain network members is determined by whether they can benefit from it. When the benefit of knowledge sharing is higher, the enterprise will change from never sharing knowledge to sharing knowledge. Evolutionary games study the evolution process of the behavior of groups. The evolutionary game can reflect the evolution process of group knowledgesharing behavior over time. Furthermore, PPP projects are characterized by a long life cycle and many participants, making it inevitable that the project will be affected by government policies, laws, regulations, markets, and nature environment factors in the implementation process. These random interference factors aggravate the contradictions between public and private sectors, affecting knowledgesharing behavior.
This study will describe the knowledge-sharing stochastic evolutionary game model for the PPP supply chain and analyze the enterprise cooperation strategy and the influencing factors of the knowledge-sharing mechanism. The objectives of this study are as follows:

(1) What is the evolutionary rule of knowledge sharing of the PPP supply chain network?

(2) What factors influence the knowledge-sharing behavior of the organization in the PPP supply chain network?

The remainder of the paper is organized as follows: Section 2 provides a literature review. The conception model of the PPP supply chain network is presented in Section 3. In Section 4, the stochastic evolutionary game model for knowledge sharing in the PPP supply chain network is built. Section 5 discusses the coefficients in the model that influence the knowledge-sharing strategy with the numerical simulation method. The conclusions are drawn in Section 6.

\section{Literature Review}

2.1. Construction Supply Chain Management. From the end of the 1980s, the construction industry has seen the launch of some supply chain management (SCM) initiatives [8-10], in order to improve internal and external efficiencies, reduce waste, and add value across the entire supply chain and try to remove their adversarial interorganizational purchasersupplier relationships and fragmented business processes [11]. SCM in the construction sector has tended to be driven by main contractors pursuing long-term relationships with large construction clients, with the benefits to main contractors, including managing market volatility and enhancing profitability [12]. Construction supply chain management (CSCM) is the management of information, flow, and money in the delivery of a construction project [13]. Hatmoko and Scott [14] defined CSCM as a system where contractors, suppliers, clients, and their agents go to work together in coordination to install and utilize information in order to produce and deliver materials, plant, temporary works, equipment, labor, or other resources for a construction project. The concept of the CSCM implicitly provides the opportunity for substantial improvements in client and stakeholder value through a strategic look at profitability.

Construction is by nature is dominated by project-based one-off transaction approaches. A proposed construction project is different and delivered to a different client comprising many fragmented self-protected entrepreneurs with paranoid attitudes [15]. Supply chains of the project-based construction industry witness inherent uncertainty associated with the schedule and specifications of the construction project rather than the procurement quantity, as is the case in process-based supply chains with recurring demands [15].

The construction supply chain (CSC) has been seen characterized by customer influence [9], number and type of stakeholders [16], make-to-order supply chain [9], fragmentation [17], temporary multiple organizations [18], buyer-supplier relationship [19], collaborative opportunities 
[20], and cyclical demand [20]. Because of the one-off transaction, short-term cooperation, temporary project organization, and project-based production in the CSC, there are little coordination and collaboration between the design professionals, main contractors, subcontractors, and suppliers involved during the life cycle of the project. The information generated by various sources contributes to the fragmentation, which eventually results in lack of communication and implementation. This situation leads to change orders, low productivity, cost and time overruns, liability claims, inadequate design specifications, conflicts, and disputes [15]. Hao et al. [21] also argued that the construction supply chain is project-oriented; thus, the end of the project may cause instability in the supply chain, which greatly reduces the efficiency of knowledge sharing.

\subsection{Knowledge Sharing in the Construction Supply Chain.} Knowledge sharing in interorganizations has attracted attention in a variety of studies in the construction supply chain. Robinson et al. [7] considered the design, architecture, surveying, and other construction services as knowledge-intensive service sectors. If the project team members come from a range of organizations, they can be highly effective and efficient working because the different organization team members create a pool of various skills and knowledge [22]. From a supply chain management perspective, the research from Nicolini et al. [23] showed that not only the material and information but also the knowledge and expertise across clusters to accomplish a task should be integrated among the supply chain partners. Briscoe and Dainty [24] considered that knowledge and expertise from suppliers subsequently add value to clients if they are involved at an early stage. In the construction supply chain, knowledge contribution was considered as important as communication and information flow. It was suggested that knowledge sharing in the construction supply chain is a vital and complex social process [25]. Styhre and Gluch [26] argued that knowledge management in the construction industry largely depends on informal networks and social capital because the participants in the construction sector focused on transactions rather than network attributes.

The knowledge management life cycle consists of five processes: discovery and capturing, organization and storage, distribution and sharing, creation and leverage, and retirement and archiving [27]. Studies show that a significant proportion of construction organizations recognizes the benefits of knowledge sharing, such as reducing rework, improved utilization of tacit knowledge, and best practices to facilitate continuous improvement and innovation [28, 29]. Therefore, an appropriate mechanism is required depending on the type of knowledge to transfer, and the other characteristics such as whether the knowledge is available internally or externally reside with particular individuals or groups [7]. Newell [30] highlighted that there is a need for organizations to have a supportive organizational culture and trust to encourage knowledge sharing.

Many factors influence knowledge-sharing behavior. Shang [31] argued that top management support, motivation, organizational culture, trust, and intention are the main factors that influence knowledge sharing. Chang et al. [32] indicated that knowledge-sharing behavior decisions are influenced by trust, commitment, and self-efficacy. Wang and Shi [27] proposed that the knowledgesharing behavior of the supply chain is determined by the value of the knowledge, the shared benefit, and the status of the enterprise. It is also found that knowledge level, assimilation capacity, and knowledge-sharing risk affect knowledge sharing among groups [33]. However, there is a lack of a structured framework in place to address knowledge sharing. The ability to learn is also crucial for effective knowledge transfer, and an organization's absorptive capacity to manage new knowledge depends on prior knowledge and technical capability [34].

2.3. Knowledge Sharing in the PPP Supply Chain. It was reported that team stability and the duration of traditional projects had a profound implication for knowledge creation and reuse [7]. Egan [5] noted that the project teams are disbanded at the end of every project and argued that the repeated selection of new teams inhibited learning, innovation, and the development of skilled and experienced teams. In PPP projects, there is the opportunity for longterm collaboration, so new knowledge can be developed through the dynamic interaction of tacit and explicit knowledge to find solutions to client requirements [7]. Collaborative working leads to knowledge integration in an informal relationship not based on contractual commitment [21]. The committed relationships in collaborative working connect all organizations tightly and intensively in a knowledge supporting network [25]. Therefore, about threequarters (76\%) of client and construction organizations (consultants and contractors) agree that there is considerable scope for learning on PPP projects [7].

In the PPP supply chain network, architects, engineers, facilities' managers, clients, and financial and technical specialists involved in PPP projects interact by using both codified and tacit knowledge during planning and design, construction, and operational phases to deliver various infrastructure project outcomes. Explicit (codified) knowledge includes architectural design philosophy, design codes of practice, engineering principles, risk allocation matrix, and value-for-money manuals in PPP projects, which are codified and easily communicated or shared with other members [7]. Tacit knowledge includes the experience of estimating the values of various risks in PPP projects, experience in tendering for PPP projects, practical design, and work programming skills on PPP projects, all of which are acquired over a period of time [7, 35].

Knowledge-sharing networks in the PPP supply chain raise complex issues such as confidentiality, reliability, copyright, the dissemination of a firm's unique stock of knowledge outside its boundaries, and the trade-off between cooperation and competition or what is referred to as "coopetition." [27] For the public sector, public managers usually have less experience with contracting for PPPs since most projects are carried out through more short-term 
contracts [36]. The bundling of responsibilities in PPP contracts also challenges government managers to face the issues they are not accustomed to considering, such as the creation of key performance indicators (KPIs) [37]. As a result, the public sector typically negotiates with a more knowledgeable private partner and faces asymmetry information regarding private sectors [38]. It was shown that a significant proportion of construction organizations recognizes the benefits of knowledge transfer, such as reducing rework, improved utilization of tacit knowledge, and best practices to facilitate continuous improvement and innovation $[39,40]$. Knowledge sharing could also be an effective way of mitigating risks, which is a critical issue in an increasingly complex PPP environment. However, implementing a knowledge strategy is still underdeveloped in client, design, and construction organizations [7].

\subsection{Evolutionary Game Theory in Supply Chain Management.} Evolutionary game theory is different from classical game theory in focusing more on the dynamics of strategy change [41]. It is influenced by the frequency of the competing strategies in the population [42]. The success of a strategy is determined by how good the strategy is in the presence of competing strategies (including itself) and of the frequency with which those strategies are used [43]. The supply chain is an ecosystem, and each node can be regarded as a living structure with learning and computing capacity [44]. Therefore, the evolutionary game method is widely used in supply chain research. Tian et al. [45] used the evolutionary game method to analyze the game relationship among governments, enterprises, and consumers. They found that government subsidies and environmental awareness were the key factors affecting the diffusion of the green supply chain. Babu and Mohan [46] and $\mathrm{Xu}$ et al. [47] used the evolutionary game method to study the sustainable development of the supply chain. At the same time, Zhang et al. applied the evolutionary game method to the study of supply chain logistics information cooperation. In terms of research on shared knowledge sharing, Hao et al. [21] used the evolutionary game method to study the evolution path and stability strategy of knowledge-sharing behavior of construction supply chain enterprises and analyzed the main factors influencing knowledge sharing of enterprises. Li and Kang [48] established an evolutionary game model from the perspective of knowledge-sharing barriers and analyzed the dynamic evolution process of enterprise knowledgesharing behaviors in supply chain networks.

\section{Conception Model of the PPP Supply Chain Network}

The core player in the construction supply chain depends on the project delivery systems. In the design-bid-build- (DBB-) based construction supply chain, the construction company is at the core place. In the design-build- (DB-) based construction supply chain, the design-builder plays the core role of the network. The PPP investment company is the core organization in the PPP supply chain. The infrastructure PPP supply chain is built on the industry chain of construction, which includes the whole life cycle industry chain of finance, design, construction, and operation. As shown in Figure 1, the PPP investment company is the core role in the PPP supply chain network. The PPP investment company has built the network, integrated the resource, and completed the delivery of the infrastructure project. On the one hand, it faced the suppliers of finance, design, construction, and operation organizations; on the other hand, it faced the demand side of the government/client or public. In the PPP investment companies, they would have dozens of infrastructure projects in a certain period, and different projects are at different stages of the life cycle. The PPP investment companies would build a supplier selection checklist in every stage, or build an industry alliance with the supplier organizations. The relatively certain suppliers in finance, design, construction, and operation stages are rigorously screened. These suppliers in the PPP supply chain network can be named supplier pool. In the arrangement of the PPP investment company, the selected suppliers take part in a proposed project, which forms a stable network of the infrastructure PPP supply chain. In the network, there are flows of material, money, and knowledge. They share resources and knowledge and strive to share information, reduce costs, and innovate technologies in the face of unified public customers, thus improving the core competitiveness of PPP investment, which is actually the core competitiveness of this supply chain network.

There are some differences between the construction supply chain and PPP supply chain, as shown in Table 1. Firstly, the orientation is different. The construction supply chain is focusing on construction production, while the PPP supply chain is product- and service-oriented. The PPP supply chain delivers the infrastructure product and public service. Secondly, the price system is different. The price of the construction supply chain is based on the bill of quantity (BOQ) of the product. However, the price of the PPP supply chain is based on the quality of service. The government/client paying for the service is based on the performance of the PPP project, which is performancebased payment. Thirdly, the core organization in the two supply chain networks is different that is discussed as in the previous section. Fourthly, the duration of cooperation varies. The business of the construction supply chain is unstable, and the construction production location is not certain but random. Therefore, cooperative enterprises are relatively short-term collaboration, and the relationship is unstable. In the PPP supply chain, a project with a long operation period can form a relatively fixed long-term cooperative relationship in a place, which is more conducive to the establishment of cooperative trust, knowledge sharing, and promotion of innovation. Finally, the length of the supply chain is different. In the construction supply chain, the cooperation between enterprises is only related to the construction stage, such as construction, material supply, equipment installation, and technical consulting services. The PPP supply chain includes financing, design, construction, operation, and 


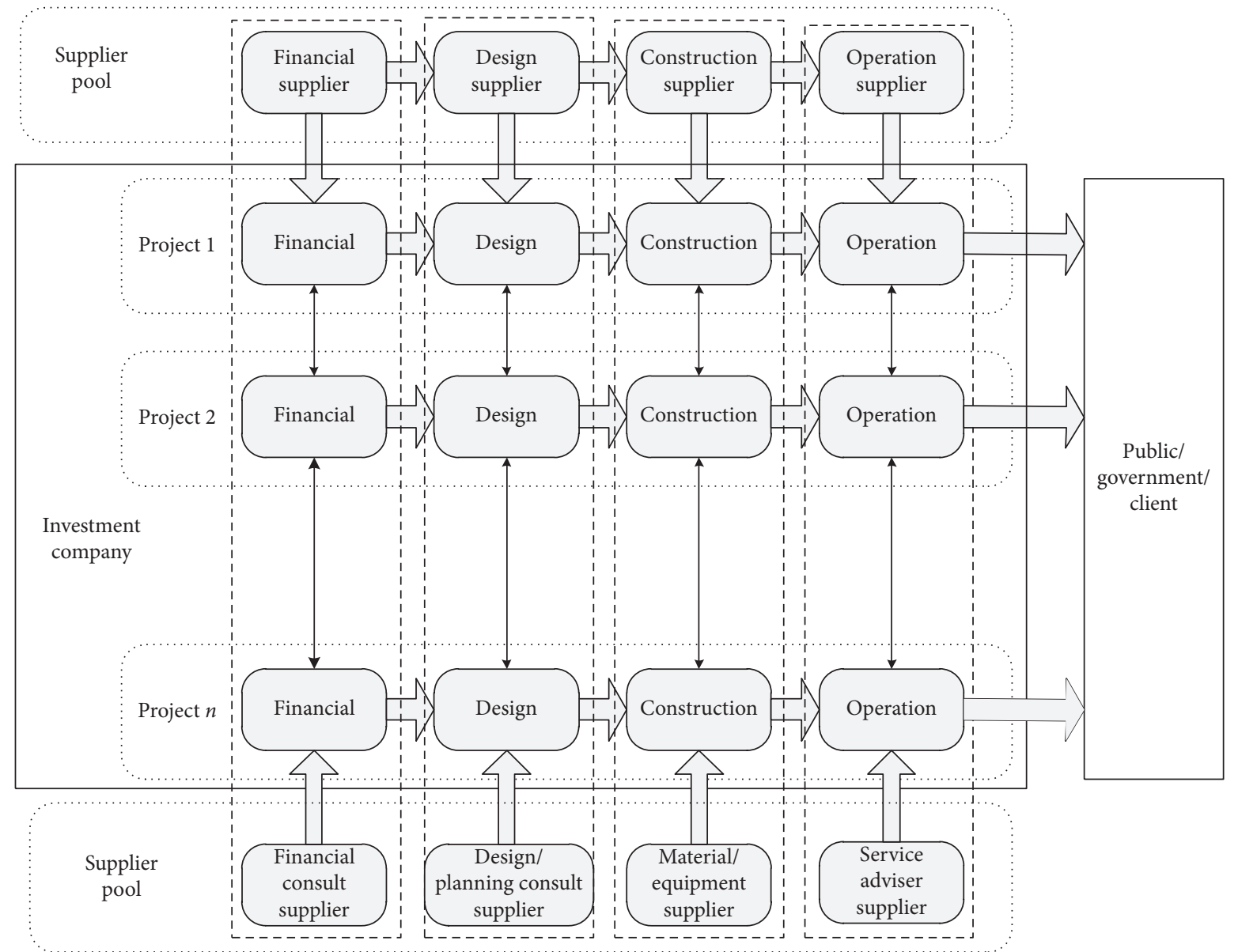

Figure 1: Infrastructure PPP supply chain network.

TABLE 1: The differences between the construction supply chain and PPP supply chain.

\begin{tabular}{lcc}
\hline Differences & Construction supply chain & PPP supply chain \\
\hline Orientation & Construction production & Product and service \\
Pricing & BOQ of the product & Performance-based payment \\
Core organization & Construction company & PPP investment company \\
Duration of cooperation & Short-term & Long-term \\
Transaction frequency & Few & Abound \\
Relationship & Stabilization & Instability \\
Length of the supply chain & Only construction & Life cycle \\
\hline
\end{tabular}

maintenance industry chain in the life cycle. In the whole chain, various enterprises can meet the continuous improvement of customer demand through information sharing and cooperation and promote the upgrading of the construction industry at the same time.

\section{Stochastic Evolutionary Game Model for Knowledge Sharing in the PPP Supply Chain Network}

The evolutionary game model is the base of the stochastic evolutionary game model. The evolutionary game model for knowledge sharing in the PPP supply chain network is firstly built.
4.1. Basic Assumptions and Variable Setting. The model is based on the following basic assumptions:

Assumption 1: the game process is based on bounded rationality and incomplete information. The players cannot fully understand the situation of their opponents and can only make decisions based on the limited information that they have. They continuously adjust their decisions based on the updated information in order to maximize their interests.

Assumption 2: assumptions about knowledge: according to the research conducted by Ritala et al. [49] and $\mathrm{Li}$ and Kang [48], it is assumed that the knowledge exists objectively and can be shared and measured quantitatively. 


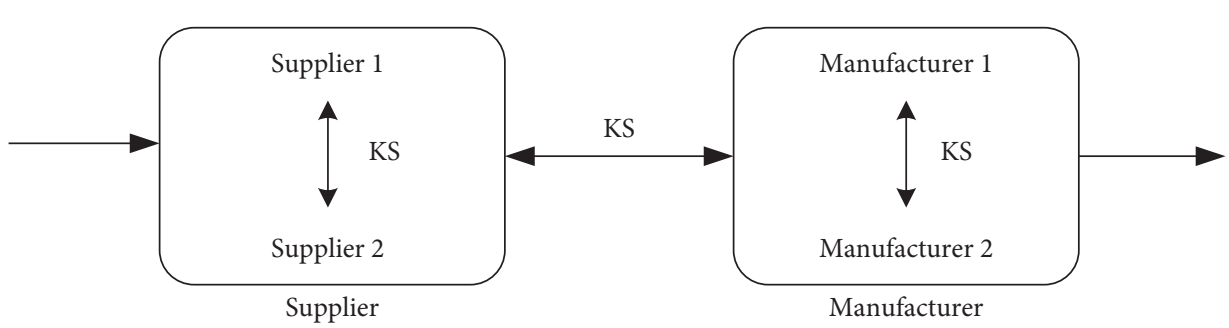

FIGURE 2: PPP supply chain knowledge-sharing model.

Assumption 3: assumptions of game players: in the PPP supply chain, knowledge sharing not only occurs between the supplier group and the manufacturer group but also exists within the two groups, as shown in Figure 2. Intergroup knowledge sharing (KS) can reduce the cost of enterprise cooperation in the supply chain and improve the competitiveness of the group. Therefore, intergroup knowledge sharing should be considered because knowledge sharing behaviors exist between two groups and within each group.

Assumption 4: in the PPP supply chain, enterprises have two behavioral choices: nonsharing and sharing. Nonsharing behavior means that one does not share his knowledge with other enterprises. Sharing represents the active sharing of knowledge with other enterprises and benefiting each other in the process of sharing knowledge. In the process of sharing, if some of the enterprises only receive knowledge and not share knowledge, the interests of the shared organization would be damaged. Such opportunistic behavior is not conducive to the evolution of the supply chain system towards the goal of knowledge value increment. So, the opportunism behavior should be punished. In order to simplify the model solving process, it is assumed that the penalty for opportunism behavior is less than the benefit earned by knowledge sharing.

Assumption 5: in the process of knowledge sharing, the status between enterprises is unequal.

In the PPP supply chain network, some of the enterprises reserve more knowledge than others and have a more vital ability to absorb and transform knowledge. That is, they possess a higher knowledge of potential and power. Therefore, they can get more additional benefits from knowledge sharing. At the same time, their corresponding risk of knowledge leakage and sharing cost will also be more significant. In this study, enterprise group 1 presents the higher knowledge power companies, while enterprise group 2 presents the ones with lower knowledge potential. What is assumed here is the unequal power of enterprises. It remains to be studied how random disturbance factors affect the knowledge-sharing behavior among enterprises when the power of enterprises is equal.

Assumption 6: evolutionary game method presents the evolutionary process of groups rather than individuals. Therefore, it is assumed that, in the initial state, the proportion of no sharing strategy selected in enterprise group 1 is $x$, and the proportion of sharing strategy selected is $(1-x)$. In enterprise group 2 , the proportion of choosing no sharing strategy is $y$, and the proportion of choosing a sharing strategy is $(1-y)$.

The variable setting and its meaning of the model are shown in Table 2, where $i=1,2$, representing enterprise group 1 and enterprise group 2, respectively.

4.2. Description of the Model. According to the above assumptions, an asymmetric evolutionary game model of knowledge sharing among enterprise groups is established based on incomplete information and bounded rationality. The enterprises choose whether or not to share knowledge according to their interests. The strategies of enterprise group 1 are (no sharing, sharing). The strategies of enterprise group 2 are (no sharing, sharing). There are four scenarios for the strategic combination of enterprise group 1 and enterprise group 2:

(1) Group 1 chooses not to share knowledge, while group 2 chooses not to share knowledge, i.e., (no sharing, no sharing)

The income of enterprise group 1 is $U_{1}$ The income of enterprise group 2 is $U_{2}$

(2) Group 1 chooses not to share knowledge, while group 2 chooses to share knowledge, i.e., (no sharing, sharing)

$$
\begin{aligned}
& \text { The income of enterprise group } 1 \text { is } \\
& U_{1}+k_{2} \beta_{1} T_{1} S_{2}-A T_{1} k_{2} S_{2} \\
& \text { The income of enterprise group } 2 \text { is } \\
& U_{2}-\lambda_{2} k_{2} S_{2}-C_{2} k_{2} S_{2}+\alpha_{2} k_{2} D S_{2}+p_{2}
\end{aligned}
$$

(3) Group 1 chooses to share knowledge, while group 2 chooses not to share knowledge, i.e., (sharing, no sharing)

The income of enterprise group 1 is $U_{1}-\lambda_{1} k_{1} S_{1}-C_{1} k_{1} S_{1}+\alpha_{1} k_{1} D S_{1}+p_{1}$ The income of enterprise group 2 is $U_{2}+k_{1} \beta_{2} T_{2} S_{1}-A T_{2} k_{1} S_{1}$

(4) Group 1 chooses to share knowledge, while group 2 chooses to share knowledge, i.e., (sharing, sharing)

The income of enterprise group 1 is $U_{1}+\alpha_{1} k_{1} D S_{1}+k_{2} \beta_{1} T_{1} S_{2}-\lambda_{1} k_{1} S_{1}-C_{1} k_{1} S_{1}$

The income of enterprise group 2 is $U_{2}+\alpha_{2} k_{2} D S_{2}+k_{1} \beta_{2} T_{2} S_{1}-\lambda_{2} k_{2} S_{2}-C_{2} k_{2} S_{2}$ 
TABLE 2: Model variables and their explanation.

\begin{tabular}{lc}
\hline Variable & Explanation \\
\hline$U_{i}$ & Benefits when the enterprise chooses no sharing behavior \\
$S_{i}$ & The amount of knowledge enterprises can share \\
$k_{i}$ & The proportion of enterprises that select sharing behavior \\
$T_{i}$ & The ability of enterprises to absorb and transform knowledge \\
$D$ & Incentive coefficient for sharing knowledge enterprise \\
$\alpha_{i}$ & Trust coefficient between enterprises \\
$\beta_{i}$ & The value-added coefficient after knowledge sharing \\
$C_{i}$ & The cost coefficient of knowledge sharing \\
$A$ & The penalty coefficient for the opportunist behavior of enterprises \\
$\lambda_{i}$ & The risk of knowledge leakage \\
$p_{i}$ & Additional benefits from knowledge sharing \\
\hline
\end{tabular}

TABle 3: Payment matrix of knowledge-sharing behavior.

\begin{tabular}{lcc}
\hline $\begin{array}{l}\text { Enterprise } \\
\text { group 1 }\end{array}$ & No sharing & Enterprise group 2 \\
\hline No sharing & $U_{1}, U_{2}$ & Sharing \\
Sharing & $U_{1}-\lambda_{1} k_{1} S_{1}-C_{1} k_{1} S_{1}+\alpha_{1} k_{1} D S_{1}+p_{1}$, & $U_{1}+k_{2} \beta_{1} T_{1} S_{2}-A T_{1} k_{2} S_{2}, U_{2}-\lambda_{2} k_{2} S_{2}-C_{2} k_{2} S_{2}+\alpha_{2} k_{2} D S_{2}+p_{2}$ \\
& $U_{2}+k_{1} \beta_{2} T_{2} S_{1}-A T_{2} k_{1} S_{1}$ & $U_{1}+\alpha_{1} k_{1} D S_{1}+k_{2} \beta_{1} T_{1} S_{2}-\lambda_{1} k_{1} S_{1}-C_{1} k_{1} S_{1}$, \\
& & $U_{2}+\alpha_{2} k_{2} D S_{2}+k_{1} \beta_{2} T_{2} S_{1}-\lambda_{2} k_{2} S_{2}-C_{2} k_{2} S_{2}$ \\
\hline
\end{tabular}

The strategy combination and income of the above enterprises can be expressed by the payment matrix, as shown in Table 3.

4.3. Establishment of the Model. According to hypothesis 6 and Table 3, it can be obtained that the expected income of enterprise group 1 choosing no sharing strategy is

$$
U_{11}=y(t) U_{1}+(1-y(t))\left(U_{1}+k_{2} \beta_{1} T_{1} S_{2}-A T_{1} k_{2} S_{2}\right) .
$$

The expected income of sharing strategy selected by enterprise group 1 is

$$
\begin{aligned}
U_{12}= & y(t)\left(U_{1}-\lambda_{1} k_{1} S_{1}-C_{1} k_{1} S_{1}+\alpha_{1} k_{1} D S_{1}+p_{1}\right) \\
& +(1-y(t))\left(U_{1}+\alpha_{1} k_{1} D S_{1}+k_{2} \beta_{1} T_{1} S_{2}-\lambda_{1} k_{1} S_{1}-C_{1} k_{1} S_{1}\right) .
\end{aligned}
$$

The average income is

$$
\bar{U}_{1}=x(t) U_{11}+(1-x(t)) U_{12} .
$$

The expected income of the no sharing strategy selected by enterprise group 2 is

$$
U_{21}=x(t) U_{2}+(1-x(t))\left(U_{2}+k_{1} \beta_{2} T_{2} S_{1}-A T_{2} k_{1} S_{1}\right) .
$$

The expected income of sharing strategy selected by enterprise group 2 is

$$
\begin{aligned}
U_{22}= & x(t)\left(U_{2}-\lambda_{2} k_{2} S_{2}-C_{2} k_{2} S_{2}+\alpha_{2} k_{2} D S_{2}+p_{2}\right) \\
& +(1-x(t))\left(U_{2}+\alpha_{2} k_{2} D S_{2}+k_{1} \beta_{2} T_{2} S_{1}-\lambda_{2} k_{2} S_{2}-C_{2} k_{2} S_{2}\right) .
\end{aligned}
$$

The average income is

$$
\bar{U}_{2}=y(t) U_{21}+(1-y(t)) U_{22} \text {. }
$$

The replication dynamic equation describes the changes of group strategies over time. The replication dynamic equation of no sharing strategies for enterprise group 1 and enterprise group 2 is

$$
\begin{aligned}
\frac{\mathrm{d} x(t)}{\mathrm{d} t}= & x(t)\left(U_{11}-\bar{U}_{1}\right) \\
= & \left(x(t)-x^{2}(t)\right)\left[y(t)\left(A T_{1} k_{2} S_{2}-p_{1}\right)\right. \\
& \left.+\left(\lambda_{1}+C_{1}-\alpha_{1} D_{1}\right) k_{1} S_{1}-A T_{1} k_{2} S_{2}\right], \\
\frac{\mathrm{d} y(t)}{\mathrm{d} t}= & y(t)\left(U_{21}-\bar{U}_{2}\right) \\
= & \left(y(t)-y^{2}(t)\right)\left[x(t)\left(A T_{2} k_{1} S_{1}-p_{2}\right)\right. \\
& \left.+\left(\lambda_{2}+C_{2}-\alpha_{2} D\right) k_{2} S_{2}-A T_{2} k_{1} S_{1}\right] .
\end{aligned}
$$

Whether an enterprise undertakes knowledge sharing or not is determined by the income from the no sharing strategy and the sharing strategy. When the income of the no sharing strategy is higher than the income of the sharing strategy, the enterprise will choose not to share knowledge; otherwise, it will take the initiative to share knowledge. Therefore, according to research $[50,51]$, equations (7) and (8) are changed to the following form: 


$$
\begin{aligned}
\frac{\mathrm{d} x(t)}{\mathrm{d} t}= & x(t)\left(U_{11}-U_{12}\right)=x(t)\left[y(t)\left(A T_{1} k_{2} S_{2}-p_{1}\right)\right. \\
& \left.+\left(\lambda_{1}+C_{1}-\alpha_{1} D\right) k_{1} S_{1}-A T_{1} k_{2} S_{2}\right] \\
\frac{\mathrm{d} y(t)}{\mathrm{d} t}= & y(t)\left(U_{21}-U_{22}\right)=y(t)\left[x(t)\left(A T_{2} k_{1} S_{1}-p_{2}\right)\right. \\
& \left.+\left(\lambda_{2}+C_{2}-\alpha_{2} D\right) k_{2} S_{2}-A T_{2} k_{1} S_{1}\right]
\end{aligned}
$$

\subsection{Stochastic Evolutionary Game Model}

4.4.1. Model Establishment. Game theory assumes that the proportion of the players choosing a strategy of the rule of change over time is determined. Whether companies choose knowledge sharing in the supply chain is influenced by random disturbance factors such as government policy and environmental changes. These factors will cause interferences with the evolution process of the knowledge-sharing behavior of the enterprise, making the behavior of the enterprise change over time as a stochastic process with uncertainty. In order to explore the influence of random disturbance factors on enterprise knowledge-sharing behavior, Gaussian white noise is introduced to establish a stochastic evolutionary game model based on the stochastic analysis theory. According to the concept of Gaussian white noise, equations (9) and (10) can be changed into the following forms:

$$
\begin{aligned}
\mathrm{d} x(t)= & x(t)\left[y(t)\left(A T_{1} k_{2} S_{2}-p_{1}\right)+\left(\lambda_{1}+C_{1}-\alpha_{1} D\right) k_{1} S_{1}\right. \\
& \left.-A T_{1} k_{2} S_{2}\right] \mathrm{d} t+\delta x(t) \mathrm{d} \omega(t),
\end{aligned}
$$

$$
\begin{aligned}
\mathrm{d} y(t)= & y(t)\left[x(t)\left(A T_{2} k_{1} S_{1}-p_{2}\right)+\left(\lambda_{2}+C_{2}-\alpha_{2} D\right) k_{2} S_{2}\right. \\
& \left.-A T_{2} k_{1} S_{1}\right] \mathrm{d} t+\delta y(t) \mathrm{d} \omega(t) .
\end{aligned}
$$

Equations (11) and (12) are Itô stochastic differential equations. In the equations, $\delta$ is the strength of random disturbance, and $\omega(t)$ is the standard one-dimensional Brown motion. Brown motion is a kind of random fluctuation phenomenon without rules, which can reflect the strategy choice of the players under random disturbance factors. $\mathrm{d} \omega(t)$ denotes the Gaussian white noise; when $t>0$, step length is $h$, and its increment $\Delta \omega(t)=\omega(t+h)-\omega(t)$ obeys normal distribution $N(0, \sqrt{h})$.

4.4.2. Model Solution. Under the influence of $\omega(t), x(t)$ changes with time into a random process, which makes the improved stochastic replication dynamic equation have an essential difference from the original equation. Therefore, the solution process becomes so complicated to be solved numerically. The standard numerical solution of the stochastic differential equation is the Milstein method and Euler method [52]. The two methods need to use the Itô formula for random Taylor expansion for stochastic differential equations. The process is as follows.
The stochastic differential equation [53] is given as follows:

$$
\mathrm{d} x(t)=f(t, x(t)) \mathrm{d} t+g(t, x(t)) \mathrm{d} \omega(t),
$$

where $t \in\left[t_{0}, T\right], x\left(t_{0}\right)=x_{0}, x_{0} \in R$, and $\omega(t)$ is the standard wiener process. Let $h=\left(T-t_{0}\right) / N$ and $t_{n}=t_{0}+n h$, and for equation (13), random Taylor expansion is carried out:

$$
\begin{aligned}
x\left(t_{n+1}\right)= & x\left(t_{n}\right)+K_{0} f\left(x\left(t_{n}\right)\right) \mathrm{d} t+K_{1} g\left(x\left(t_{n}\right)\right) \\
& +K_{11} M^{1} g\left(x\left(t_{n}\right)\right)+K_{00} M^{0} f\left(x\left(t_{n}\right)\right)+R,
\end{aligned}
$$

where $R$ represents the remaining term and satisfies

$$
\begin{aligned}
M^{0} & =f(x) \frac{\partial}{\partial x}+\frac{1}{2} g^{2}(x) \frac{\partial^{2}}{\partial x^{2}}, \\
M^{1} & =g(x) \frac{\partial}{\partial x}, \\
K_{0} & =h, \\
K_{1} & =\Delta \omega_{n}, \\
K_{00} & =\frac{1}{2} h^{2}, \\
K_{11} & =\frac{1}{2}\left[\left(\Delta \omega_{n}\right)^{2}-h\right] .
\end{aligned}
$$

According to equation (14), Taylor expansion of equations (11) and (12) can be obtained:

$$
\begin{aligned}
x\left(t_{n+1}\right)= & x\left(t_{n}\right)+h x\left(t_{n}\right)\left[y\left(t_{n}\right)\left(A T_{1} k_{2} S_{2}-p_{1}\right)\right. \\
& \left.+\left(\lambda_{1}+C_{1}-\alpha_{1} D\right) k_{1} S_{1}-A T_{1} k_{2} S_{2}\right] o \\
& +\Delta \omega_{n}\left(\delta x\left(t_{n}\right)\right)+\frac{1}{2}\left[\left(\Delta \omega_{n}\right)^{2}-h\right]\left(\delta x\left(t_{n}\right)\right)+\frac{1}{2} h^{2} x\left(t_{n}\right) \\
& \cdot\left[y\left(t_{n}\right)\left(A T_{1} k_{2} S_{2}-p_{1}\right)+\left(\lambda_{1}+C_{1}-\alpha_{1} D\right) k_{1} S_{1}-A T_{1} k_{2} S_{2}\right] \Delta \\
& \cdot\left[y\left(t_{n}\right)\left(A T_{1} k_{2} S_{2}-p_{1}\right)+\left(\lambda_{1}+C_{1}-\alpha_{1} D\right) k_{1} S_{1}-A T_{1} k_{2} S_{2}\right]+R_{1}, \\
y\left(t_{n+1}\right)= & y\left(t_{n}\right)+h y\left(t_{n}\right)\left[x\left(t_{n}\right)\left(A T_{2} k_{1} S_{1}-p_{2}\right)\right. \\
& \left.+\left(\lambda_{2}+C_{2}-\alpha_{2} D\right) k_{2} S_{2}-A T_{2} k_{1} S_{1}\right] \\
& +\Delta \omega_{n}\left(\delta y\left(t_{n}\right)\right)+\frac{1}{2}\left[\left(\Delta \omega_{n}\right)^{2}-h\right]\left(\delta y\left(t_{n}\right)\right)+\frac{1}{2} h^{2} y\left(t_{n}\right) \\
& \cdot\left[x\left(t_{n}\right)\left(A T_{2} k_{1} S_{1}-p_{2}\right)+\left(\lambda_{2}+C_{2}-\alpha_{2} D\right) k_{2} S_{2}-A T_{2} k_{1} S_{1}\right] \Delta \\
& \cdot\left[x\left(t_{n}\right)\left(A T_{2} k_{1} S_{1}-p_{2}\right)+\left(\lambda_{2}+C_{2}-\alpha_{2} D\right) k_{2} S_{2}-A T_{2} k_{1} S_{1}\right]+R_{2} .
\end{aligned}
$$

Based on the above Taylor expansion formula, we used the Milstein method to solve the stochastic evolution equation of knowledge sharing in the PPP supply chain numerically: 


$$
\begin{aligned}
x\left(t_{n+1}\right)= & x\left(t_{n}\right)+h f\left(x\left(t_{n}\right)\right) \mathrm{d} t+\Delta \omega_{n} g\left(x\left(t_{n}\right)\right) \\
& +\frac{1}{2}\left[\left(\Delta \omega_{n}\right)^{2}-h\right] g\left(x\left(t_{n}\right)\right) g^{\prime}\left(x\left(t_{n}\right)\right) .
\end{aligned}
$$

According to equation (17), stochastic differential equations (11) and (12) are numerically solved, and the evolution results can be obtained.

4.4.3. Stability Discrimination of Solutions. According to the research of Baker and Buckwar [54], the following method was used to determine the stability solution of the equation.

Lemma 1. Assuming stochastic process $X=\{X(t), t \geq 0\}$ It $\widehat{o}$, differential equation solution of the initial value problems is as follows

$$
\left\{\begin{array}{l}
\mathrm{d} X(t)=f(t, X(t)) \mathrm{d} t+g(t, X(t)) \mathrm{d} \omega(t), \quad \forall t \geq 0, \\
X\left(t_{0}\right)=x_{0} .
\end{array}\right.
$$

It is assumed that the continuous function $V(t, x)$ and the normal number $c_{1}, \quad c_{2}$ exist, which makes $c_{1}|x|^{p} \leq V(t, x) \leq c_{2}|x|^{p}$.

(1) If there are constant $\gamma, L V(t, x) \leq-\gamma V(t, x)$, the order $p$ expected moment exponential of the initial solution for equation (18) would be stable, and $E|x(t, x)|^{p}<\left(c_{2} / c_{1}\right)\left|x_{0}\right|^{p} e^{-\gamma t}, t \geq 0, \quad$ can $\quad$ be established

(2) If there are constant $\gamma, L V(t, x) \geq \gamma V(t, x)$, the order $p$ expected moment exponential of the initial solution for equation (18) would not be stable, and $E|x(t, x)|^{p} \geq\left(c_{2} / c_{1}\right)\left|x_{0}\right|^{p} e^{-\gamma t}, t \geq 0, \quad$ can $\quad$ be established

Here, $\quad L V(t, x)=V_{t}(t, x)+V_{x}(t, x) f(t, x)+1 / 2 g^{2}(t, x)$ $V_{x x}(t, x)$.

According to Lemma 1, given equations (11) and (12), let $V(t, x)=x(t), x(t) \in[0,1]$, let $V(t, y)=y(t), y(t) \in[0,1]$, $c_{1}=c_{2}=1, p=1, \gamma=1, L V(t, x)=x(t)\left[y(t)\left(A T_{1} k_{2} S_{2}-\right.\right.$ $\left.\left.p_{1}\right)+\left(\lambda_{1}+C_{1}-\alpha_{1} D\right) k_{1} S_{1}-A T_{1} k_{2} S_{2}\right], \quad$ and $L V(t, y)=$ $y(t)\left[x(t)\left(A T_{2} k_{1} S_{1}-p_{2}\right)+\left(\lambda_{2}+C_{2}-\alpha_{2} D\right) k_{2} S_{2}-A T_{2} k_{1} S_{1}\right]$.

If the zero solutions of the expecting moment exponential for equations (11) and (12) are stable, $L V(t, x) \leq-$ $x(t)$ and $L V(t, y) \leq-y(t)$ should be satisfied, namely,

$$
\begin{aligned}
& x(t)\left[y(t)\left(A T_{1} k_{2} S_{2}-p_{1}\right)\right. \\
& \left.\quad+\left(\lambda_{1}+C_{1}-\alpha_{1} D\right) k_{1} S_{1}-A T_{1} k_{2} S_{2}\right] \leq-x(t), \\
& y(t)\left[x(t)\left(A T_{2} k_{1} S_{1}-p_{2}\right)\right. \\
& \left.\quad+\left(\lambda_{2}+C_{2}-\alpha_{2} D\right) k_{2} S_{2}-A T_{2} k_{1} S_{1}\right] \leq-y(t) .
\end{aligned}
$$

Moreover, because $x(t), y(t) \in[0,1]$, after simplification of the above equations, a condition that strictly meets equation (19) can be obtained as follows:

$$
\alpha_{1} k_{1} D S_{1}+p_{1}-\left(\lambda_{1}+C_{1}\right) k_{1} S_{1}-1 \geq 0 .
$$

The condition that strictly meets equation (20) is

$$
\alpha_{2} k_{2} D S_{2}+p_{2}-\left(\lambda_{2}+C_{2}\right) k_{2} S_{2}-1 \geq 0 .
$$

\section{Numerical Simulation and Discussion}

Given the random disturbance factor, the influence of the main parameters on the knowledge-sharing strategy in the PPP supply chain is carried out in the numerical simulation way for equations (11) and (12) with Matlab 2018a. When each variable is assigned, the constraint conditions of equations (21) and (22) should be satisfied; that is, the constraint conditions of the expected moment exponential stability of the zero solution of equations (11) and (12) should be satisfied. The initial values of each parameter are set, as shown in Table 4. Let the step length $h=0.01$ and the intensity of random disturbance $\delta=3$.

Due to the randomness of each simulation, the single simulation result is not representative, so multiple simulations are conducted. After the invalid results are eliminated, 50 valid simulation results are recorded. The average value of these 50 simulation results is calculated and shown in the figures. The simulation results are shown in Figures 3-14. In the figures, the $x$-axis represents the number of iterations, and the $y$-axis represents the proportion of no sharing strategy selected in the enterprise group.

In order to illustrate the simulation processes, the incentive coefficient $D$ of enterprise group 1 is taken as an example; the steps are as follows:

Step 1: determine the parameter range. The change range of $D_{1}$ of enterprise group 1 increases from 0.5 to 1.5 , that is, $D_{1}=0.5, D_{1}=1$, and $D_{1}=1.5$, respectively.

Step 2: substitute parameters $D_{1}=0.5, D_{1}=1$, and $D_{1}=1.5$, and set the other parameter values according to Table 4 . The values of each parameter are substituted into equations (11) and (12), and three groups of stochastic differential equations can be obtained.

Step 3: numerical simulation: Matlab 2018a is used to numerically solve the solutions of stochastic differential equations in Step 2, and the figure is drawn in Figure 3. Take the step length $h=0.01$ and the intensity of random disturbance $\delta=3$. The number of samples (also known as iterations) is set to 200. The $x$-axis $N$ represents the number of sampling times (iterations), and the $y$-axis represents the proportion of the nonsharing strategy selected in the enterprise group.

Step 4: data recording: if the simulation results in Step 3 meet the conditions (the value of the simulation results should be between 0 and 1), the simulation results will be recorded. If the conditions are not met, continue the simulation until 50 sets of valid simulation data are collected.

Step 5: data processing: the average value of 50 groups of data obtained in Step 4 is calculated, and the incentive 
TABLE 4: Initial values of each parameter.

\begin{tabular}{lllllllllllll}
\hline Enterprise & $x$ & $U_{1}$ & $S_{1}$ & $k_{1}$ & $T_{1}$ & $\beta_{1}$ & $C_{1}$ & $\lambda_{1}$ & $\alpha_{1}$ & $p_{1}$ & $D$ & $A$ \\
group 1 & 0.5 & 20 & 8 & 0.3 & 0.8 & 0.8 & 0.6 & 0.6 & 0.6 & 4 & 1 & 1 \\
\hline Enterprise & $y$ & $U_{2}$ & $S_{2}$ & $k_{2}$ & $T_{2}$ & $\beta_{2}$ & $C_{2}$ & $\lambda_{2}$ & $\alpha_{2}$ & $p_{2}$ & & \\
group 2 & 0.5 & 15 & 5 & 0.2 & 0.5 & 0.5 & 0.5 & 0.5 & 0.8 & 3 & & \\
\hline
\end{tabular}

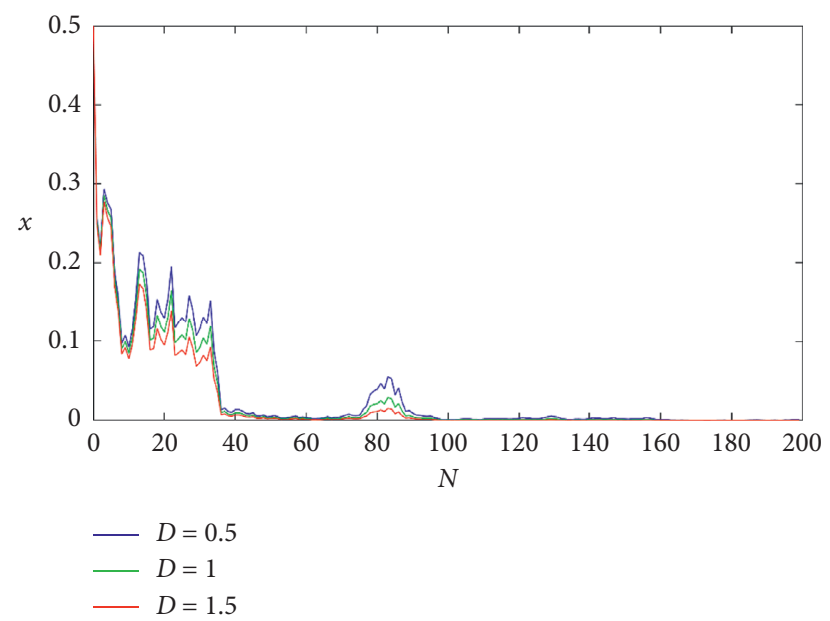

FIGURE 3: Strategy selection of enterprise group 1 affected by the incentive coefficient (single simulation).

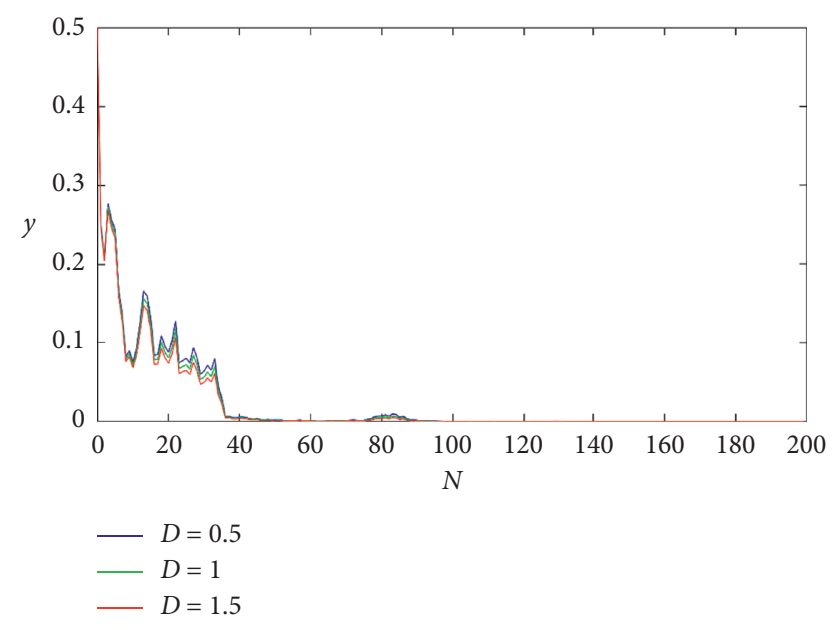

FIGURE 4: Strategy selection of enterprise group 2 affected by the incentive coefficient (single simulation).

coefficient of enterprise group 1 can be divided into the average change image of strategy selection when $D_{1}=0.5, D_{1}=1$, and $C_{1}=1.5$, as shown in Figure 5 . The calculation formula of the mean value is as follows:

$$
\bar{X}_{i}=\frac{1}{50} \sum_{n=1}^{50} X_{n}^{i}
$$

where $n=1,2, \ldots, 50$ represents the number of simulations, $X_{n}^{i}$ represents the value of the $i$ sampling at the $n$ simulation, and $\bar{X}_{i}$ represents the average value of the $i$ sampling.

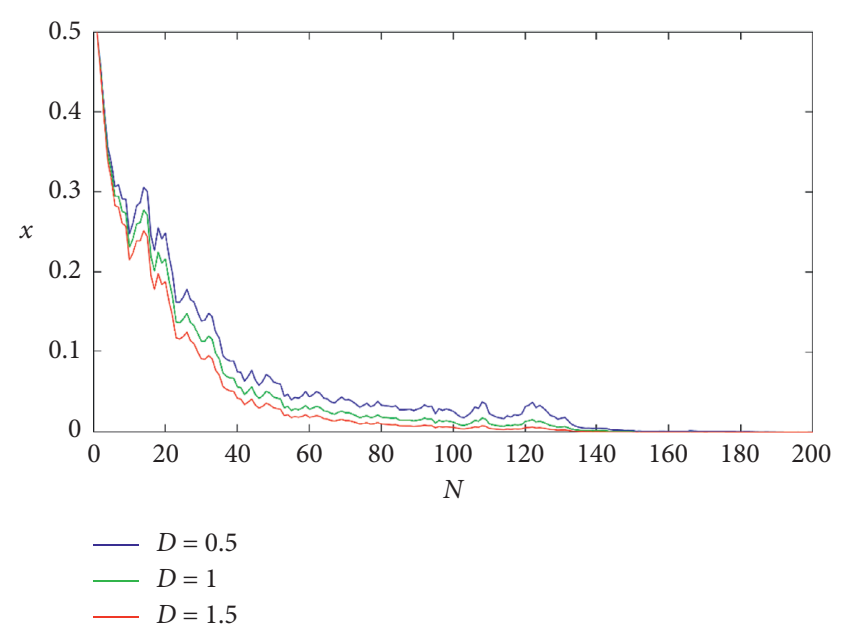

FIgURE 5: Strategy selection of enterprise group 1 affected by the incentive coefficient (average of 50 simulations).

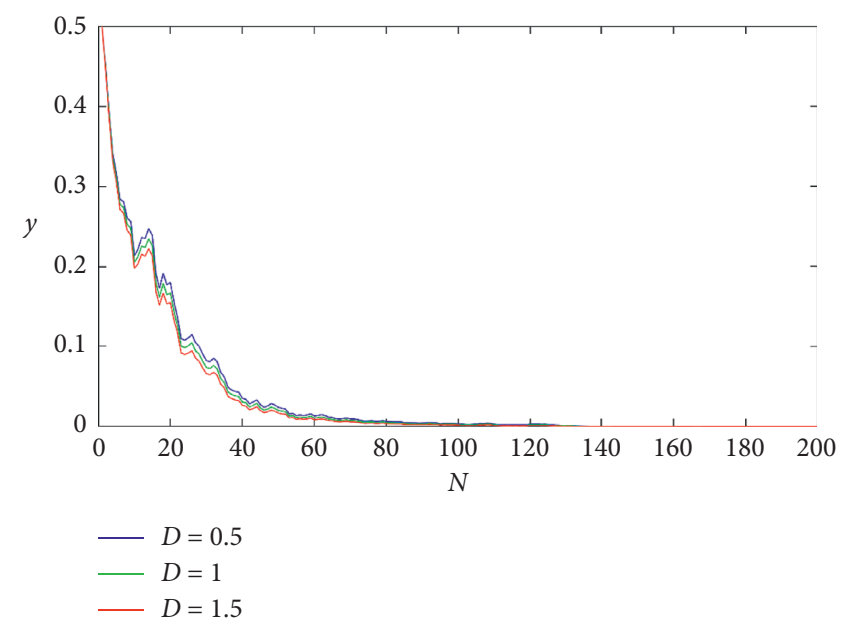

FIgURE 6: Strategy selection of enterprise group 2 affected by the incentive coefficient (average of 50 simulations).

Step 6: calculating the cumulative difference (CD) and variance $(V)$ of the simulation results: the average values were obtained in Step 5. Due to the existence of random factors, the curves of each parameter change are vastly different. Here, only the cumulative difference and variance of the first 100 samples (iterations) were calculated when the parameters change. For example, when $D_{1}=0.5$ changes to $D_{1}=1$, the calculation formula is as follows:

$$
\mathrm{CD}_{0.5 \longrightarrow 1}=\sum_{i=1}^{100}\left(\bar{X}_{i}-\bar{x}_{i}\right)
$$

$\bar{X}_{i}$ represents the mean value of the $i$ sampling when $C_{1}=1$, and $\bar{x}_{i}$ represents the mean value of the $i$ sampling when $C_{1}=0.5$. The calculation formula of variance $(V)$ is as follows: 


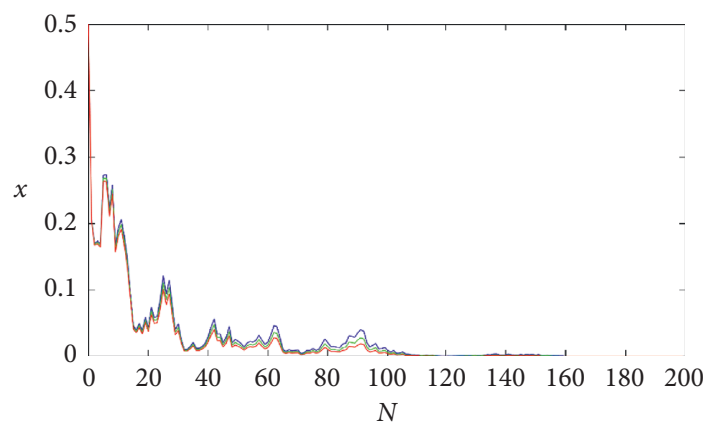

$-A=0.5$

$$
\text { - } A=1
$$$$
\text { - } A=1.5
$$

FIGURE 7: Strategy selection of enterprise group 1 affected by the penalty coefficient (single simulation).

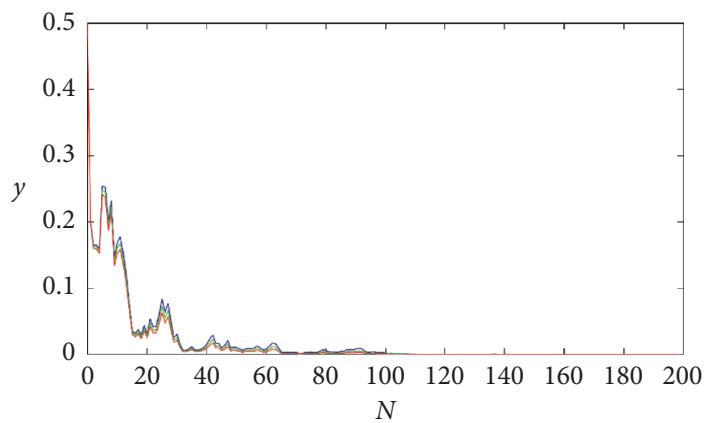

$$
\begin{aligned}
A & =0.5 \\
-A & =1 \\
-A & =1.5
\end{aligned}
$$

FIGURE 8: Strategy selection of enterprise group 2 affected by the penalty coefficient (single simulation).

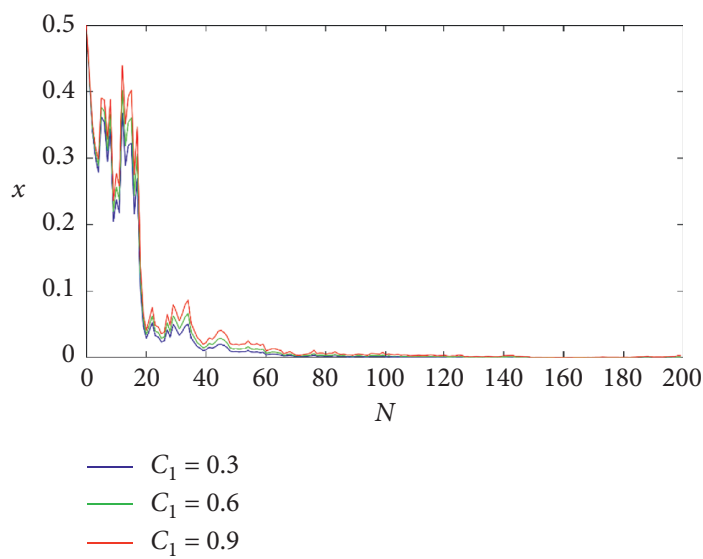

FIGURE 9: Strategy selection of enterprise group 1 affected by the cost coefficient (single simulation).

$$
V_{0.5 \longrightarrow 1}=\frac{1}{50} \sum_{n=1}^{50}\left(\frac{1}{100} \sum_{i=1}^{100}\left(X_{i}^{n}-x_{i}^{n}\right)^{2}\right)
$$

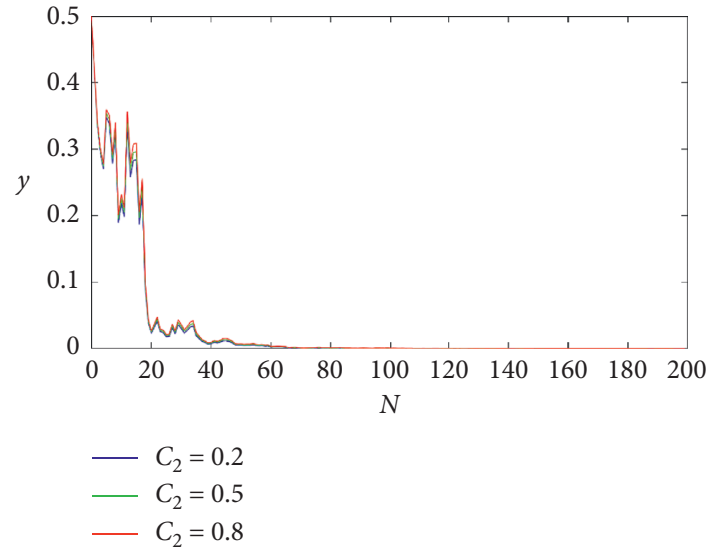

FIGURE 10: Strategy selection of enterprise group 2 affected by the cost coefficient (single simulation).

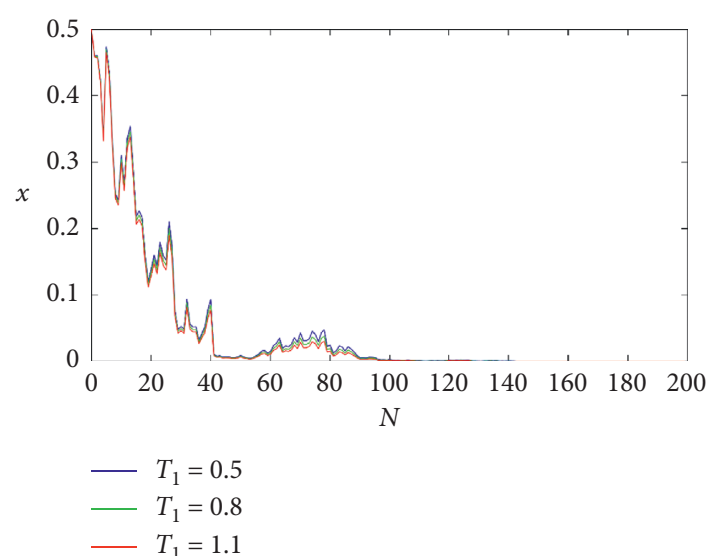

FIgURE 11: Strategy selection of enterprise group 1 affected by the transformation ability (single simulation).

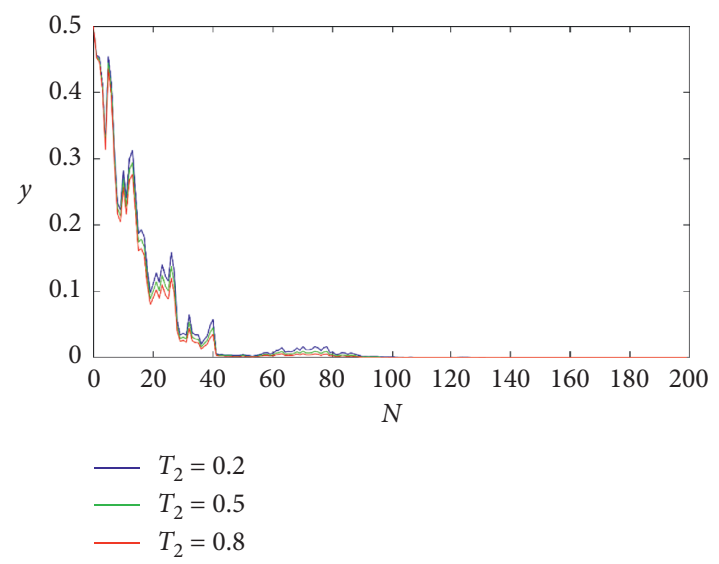

FIgURE 12: Strategy selection of enterprise group 2 affected by the transformation ability (single simulation).

The simulation data of different parameters are shown in Table 5. The cumulative difference $(C D)$ and variance $(V)$ are employed to describe the change of amplitude of enterprise 


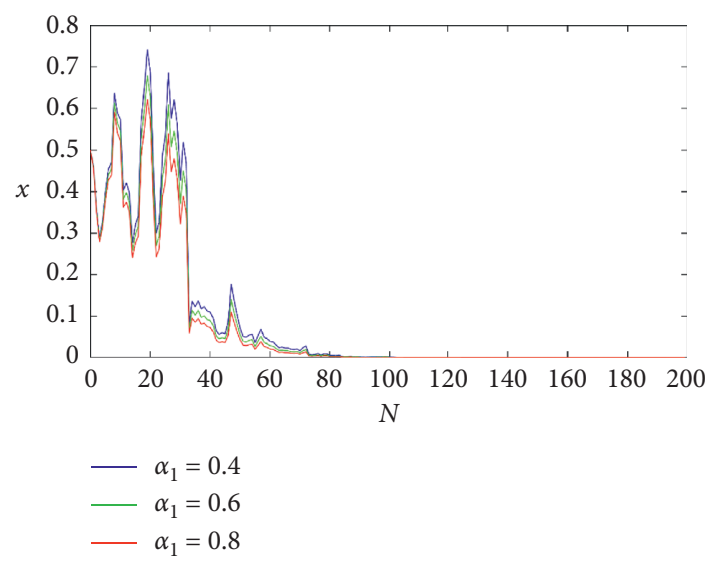

Figure 13: Strategy selection of enterprise group 1 affected by the trust coefficient (single simulation).

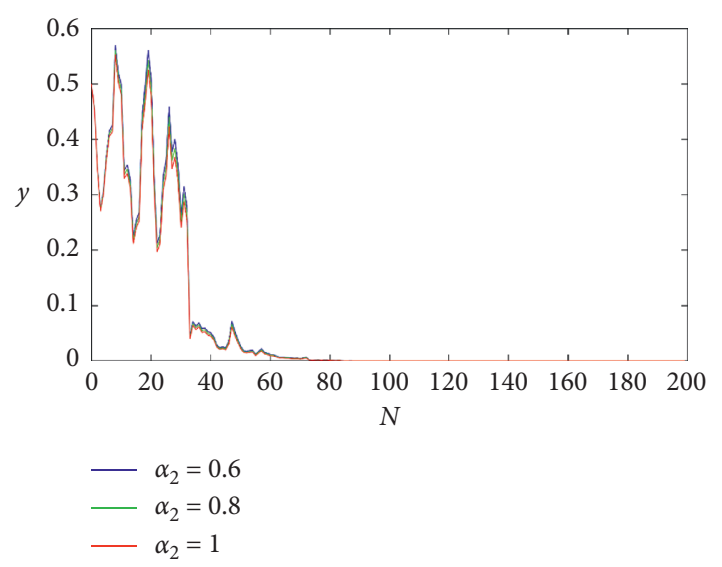

Figure 14: Strategy selection of enterprise group 2 affected by the trust coefficient (single simulation).

strategy selection when parameters change. The maximum difference value of sampling times when the proportion of subject strategy selection reaches 0 for the first time is used to reflect the convergence speed of enterprise strategy selection when parameters are changing. In Table 5, cumulative difference (CD) is the average value of the first 100 samples compared with the minimum value of the parameter. The variance $(V)$ is the variance of cumulative difference (CD). The iteration is the number of iterating that the selection ratio first reaches 0 . The iteration difference is the maximum difference of iterations when the player strategy selection ratio reaches 0 for the first time.

5.1. Strategy Selection Affected by the Incentive Coefficient. The results of the single simulation for enterprise group 1 and enterprise group 2 are shown in Figures 3 and 4, respectively. The average results of the 50 simulations for enterprise group 1 and enterprise group 2 are shown in Figures 5 and 6, respectively.

As can be seen from Figures 3-6, the higher the incentive coefficient is, the lower the proportion of enterprises choosing no sharing strategy will be. It indicates that increasing incentives has a positive motivation effect on enterprises to reduce the proportion of choosing no sharing strategy. The specific change trends are shown in Table 5 and Figures 5 and 6 . When the incentive coefficient $D$ increases from 0.5 to 1.5 , the cumulative difference of enterprise group 1 is -3.165 , the variance is 0.001 , and the maximum difference when the strategy selection ratio reaches 0 for the first time is 40 . The cumulative difference of enterprise group 2 is -0.9007 , the variance is 0.0002 , and the maximum difference when the strategy selection ratio first reached 0 is 5. The increase of the incentive coefficient has a great influence on the change range and convergence speed of strategy selection of enterprise group 1, but has a less significant influence on enterprise group 2. That is, enterprise group 1 is more sensitive to changing of the incentive coefficient. Therefore, when the PPP supply chain takes incentive measures to stimulate the behavior of the enterprise group, the incentive effect of enterprise group 1 is obviously better than that of enterprise group 2 .

5.2. Strategy Selection Affected by the Penalty Coefficient. The results of the single simulation for enterprise group 1 and enterprise group 2 are shown in Figures 7 and 8, respectively.

As can be seen from Figures 7 and 8, the increase of penalty coefficient $A$ can reduce the proportion of no sharing strategies in the enterprise group. It indicates that the increase in the penalty can restrain the speculative behavior of the enterprise groups. According to Table 5, when the penalty coefficient $A$ increases from 0.5 to 1.5 , the cumulative difference of enterprise group 1 is -1.573 , the variance is 0.0006 , and the maximum difference when the strategy selection reaches 0 for the first time is 35 . The cumulative difference of enterprise group 2 is -1.2958 , the variance is 0.0004 , and the maximum difference when the strategy selection first reaches 0 is 18 . With the increasing of the penalty coefficient, the range and convergence speed of strategy selection of enterprise group 1 are greater than those of enterprise group 2. If the PPP supply chain takes penalty measures to regulate the knowledge-sharing behavior, the restraint effect on enterprise group 1 would be more significant.

As shown in Table 5, it can be found that when the penalty coefficient $A$ increases from 0.5 to 1.5 , the cumulative difference of enterprise group 1 is -1.573 , the variance is 0.0006 , and the maximum difference when the strategy chooses to reach 0 for the first time is 35 . By comparing the influence of the incentive coefficient and penalty coefficient on the enterprise group in Table 5, the influence of the increase of the incentive coefficient on the change range and convergence speed of enterprise group 1 strategy selection is greater than that of the penalty coefficient. Similarly, it can be found that the influence of the penalty coefficient on the variation range and convergence speed of strategy selection of enterprise group 2 is more significant than that of the incentive coefficient. That is, enterprise group 1 is more sensitive to the incentive coefficient, while enterprise group 2 is more sensitive to the penalty coefficient. 
TABle 5: Simulation results of parameters.

\begin{tabular}{|c|c|c|c|c|c|c|}
\hline Parameters & Value & & Cumulative difference (CD) & Variance $(V)$ & Iteration & Iteration difference \\
\hline \multirow{6}{*}{ Incentive coefficient $D$} & \multirow{3}{*}{ Enterprise group 1} & 0.5 & 0 & 0 & 184 & 40 \\
\hline & & 1 & -1.824 & 0.001 & 151 & \\
\hline & & 1.5 & -3.165 & 0.003 & 144 & \\
\hline & \multirow{3}{*}{ Enterprise group 2} & 0.5 & 0 & 0 & 134 & 5 \\
\hline & & 1 & -0.4715 & 0.0001 & 133 & \\
\hline & & 1.5 & -0.9007 & 0.0002 & 129 & \\
\hline \multirow{6}{*}{ Penalty coefficient $A$} & \multirow{3}{*}{ Enterprise group 1} & 0.5 & 0 & 0 & 190 & 35 \\
\hline & & 1 & -0.822 & 0.0002 & 163 & \\
\hline & & 1.5 & -1.573 & 0.0006 & 155 & \\
\hline & \multirow{3}{*}{ Enterprise group 2} & 0.5 & 0 & 0 & 144 & 18 \\
\hline & & 1 & -0.6875 & 0.0001 & 132 & \\
\hline & & 1.5 & -1.2958 & 0.0004 & 126 & \\
\hline \multirow{6}{*}{ Cost coefficient $C_{i}$} & \multirow{3}{*}{ Enterprise group 1} & 0.3 & 0 & 0 & 147 & 37 \\
\hline & & 0.6 & 1.445 & 0.0005 & 163 & \\
\hline & & 0.9 & 3.461 & 0.0032 & 184 & \\
\hline & \multirow{3}{*}{ Enterprise group 2} & 0.2 & 0 & 0 & 111 & 6 \\
\hline & & 0.5 & 0.3268 & 0.0000 & 113 & \\
\hline & & 0.8 & 0.6753 & 0.0001 & 117 & \\
\hline \multirow{6}{*}{ Transformation ability $T_{i}$} & \multirow{3}{*}{ Enterprise group 1} & 0.5 & 0 & 0 & 190 & 33 \\
\hline & & 0.8 & -0.578 & 0.0001 & 181 & \\
\hline & & 1.1 & -1.134 & 0.0005 & 157 & \\
\hline & \multirow{3}{*}{ Enterprise group 2} & 0.2 & 0 & 0 & 144 & 18 \\
\hline & & 0.5 & -0.8270 & 0.0002 & 133 & \\
\hline & & 0.8 & -1.4997 & 0.0006 & 126 & \\
\hline \multirow{6}{*}{ Trust coefficient $\alpha_{i}$} & \multirow{3}{*}{ Enterprise group 1} & 0.4 & 0 & 0 & 190 & 39 \\
\hline & & 0.6 & -1.361 & 0.0005 & 160 & \\
\hline & & 0.8 & -2.452 & 0.0017 & 151 & \\
\hline & \multirow{3}{*}{ Enterprise group 2} & 0.6 & 0 & 0 & 133 & 4 \\
\hline & & 0.8 & -0.2460 & 0.0000 & 132 & \\
\hline & & 1 & -0.4728 & 0.0001 & 129 & \\
\hline
\end{tabular}

5.3. Strategy Selection Affected by the Cost Coefficient. The results of the single simulation for enterprise group 1 and enterprise group 2 are shown in Figures 9 and 10, respectively.

As can be seen from Figures 9 and 10, with the increase in cost coefficient, the proportion of enterprises choosing no sharing strategy increases. Because the increasing cost coefficient would raise the sharing cost and reduce the income of enterprises, it would lead to an increase in the proportion of enterprises choosing no sharing strategy. As shown in Table 5 , when the cost coefficient $C_{1}$ increases from 0.3 to 0.9 , the cumulative difference of enterprise group 1 is 3.461 , the variance is 0.0032 , and the maximum difference when the strategy selection reaches 0 for the first time is 37 . When the cost coefficient $C_{2}$ increases from 0.2 to 0.8 , the cumulative difference and variance of enterprise group 2 are 0.6753 and 0.0001 , respectively. Moreover, the maximum difference when the strategy selection reaches 0 for the first time is 6 . The increase in cost coefficient has a significant influence on the change range and convergence speed of strategy selection of enterprise group 1. However, it has a less significant influence on enterprise group 2. Therefore, reducing sharing costs can effectively promote enterprises to participate in knowledge sharing.
5.4. Strategy Selection Affected by the Transformation Ability. The results of the single simulation for enterprise group 1 and enterprise group 2 are shown in Figures 11 and 12, respectively.

As can be seen from Figures 11 and 12, improving the transformation ability of shared knowledge, the proportion of choosing no sharing strategy decreases gradually. The reason is that the improvement of the transformation ability enables enterprises to transform and utilize the received knowledge more efficiently and improve the conversion rate of knowledge. According to Table 5, when the transformation ability of enterprise group $1 T_{1}$ increases from 0.5 to 1.1 , the cumulative difference of enterprise group 1 is -1.134 , the variance is 0.0005 , and the maximum difference when the strategy selection reaches 0 for the first time is 33 . When the transformation ability $T_{2}$ increases from 0.2 to 0.8 , the cumulative difference of enterprise group 2 is -1.4997 , the variance is 0.0006 , and the maximum difference when the strategy selection reaches 0 for the first time is 18 . What can be seen is that the improvement of the transformation ability has an impact on the strategy selection of both groups. The impact on enterprise group 1 is mainly in accelerating the convergence speed of strategy selection, while the impact on enterprise group 2 is mainly in the change range of strategy selection. 
5.5. Strategy Selection Affected by the Trust Coefficient. The results of the single simulation for enterprise group 1 and enterprise group 2 are shown in Figures 13 and 14, respectively.

In Figures 13 and 14, $\alpha_{1}$ represents the trust degree of enterprise group 1 to enterprise group 2, and $\alpha_{2}$ represents the trust degree of enterprise group 2 to enterprise group 1 . It can be seen that when the trust coefficient between enterprise groups increases, the proportion of enterprises choosing no sharing strategy will decrease. According to Table 5, when the trust coefficient $\alpha_{1}$ increases from 0.4 to 0.8 , the cumulative difference of enterprise group 1 is -2.452 , the variance is 0.0017 , and the maximum difference when the strategy selection first reaches 0 is 39 . When the trust coefficient $\alpha_{2}$ increases from 0.6 to 1 , the cumulative difference of enterprise group 2 is -0.4728 , the variance is 0.0001 , and the maximum difference when the strategy selection reaches 0 for the first time is 4 . When the trust coefficient $\alpha_{1}$ increases, the variation range and convergence speed of the strategy selection of enterprise group 1 will be significantly affected. However, enterprise group 2 is not very sensitive to the change of the trust coefficient.

According to the above simulation results and analysis, it can be found that the proportion of no sharing strategies in enterprise group 1 and enterprise group 2 tends to 0 as the iterations increase, and eventually, both will choose the knowledge-sharing strategy. Besides, it can be seen from Table 5 that the influence of each parameter change on enterprise group 1 is more significant than that of enterprise group 2. As to the convergence rate of strategy selection, enterprise group 2 is faster than enterprise group 1. This is because when the two parties involved in knowledge sharing in the PPP supply chain have unequal positions, a company with a strong knowledge position would share more knowledge and play a leading role in knowledgesharing cooperation. Therefore, the influence of various parameter changes on knowledge sharing is more significant. However, the enterprise with weak power in the knowledge position has less knowledge stock, can get more information from the knowledge-sharing behavior, and can have more willingness to participate in knowledge sharing. Therefore, compared with the powerful knowledge organization, the organization at the weak knowledge position will choose the knowledge sharing strategy more preferentially.

Some previous research studies have indicated that some factors such as self-efficacy, mutual benefit, knowledge value, personal benefit, and benefit of knowledge sharing are the key factors that influence knowledge sharing [27, 31, 32]. It was suggested that the exchange of high-quality information and reliable communication standards act as important facilitators for process integration and consequently for building more trustful relationships in collaboration agreements [55]. Moreover, the different status of members in the PPP supply chain will generate dependence phenomenon. Dependence exists when one company does not control all of the conditions necessary for achievement of desired outcomes performed by the other party [56]. There are three critical factors that affect dependence: importance of the organizational resources, the existence of resource alternatives, and importance of the company interest in these resources [57]. The degree of trust between companies is related to a given company's dependence on its partners, which is the interorganizational trust asymmetry [58]. Our research suggests that critical factors' dependence and trust asymmetry would affect the knowledge-sharing behavior. Meanwhile, the findings of this study suggest that introducing incentive measures and trust has positive effects concerning knowledge sharing. Aerts and Haezendonck [59] argued that knowledge transfer intent or motivation, which was impacted as the partner characteristics, may trigger reluctance or increased motivation towards the transferal of knowledge. The results from this study further verify that transformation ability and knowledge power position are critical influencing factors for knowledge sharing. As the knowledge-sharing system was more efficient in providing access to information and in transferring knowledge from one organization to another, this would impact the effectiveness of the transfer through both enabling the ability to search for as well as share and apply knowledge that was sourced in an interorganizational manner [60].

\section{Conclusions and Implications}

Infrastructure PPP projects involve long-term commitment and supply chain networking across different organizations such as financiers, engineers, contractors, and other team members with specific functional relationships in the special purpose vehicle (SPV) to deliver services according to output specification [7]. Various organizations in the PPP supply chain have to share knowledge and collaborate to develop the proposed solutions that meet the needs of the public sector. This knowledge-sharing behavior is carried out in complexity and uncertainty environment. In this study, based on the evolutionary game model, Gaussian white noise is introduced into establishing a stochastic evolutionary game model to explore the evolution process of knowledgesharing behavior among members of the PPP supply chain under the influence of random disturbance factors. In order to determine how the coefficients in the model influence the knowledge-sharing strategy of the organizations in the PPP supply chain network, the sensitivity of the incentive, penalty, cost, trust, and transformation ability coefficients is analyzed with numerical simulation. The following conclusions are drawn:

(1) First of all, it is found that if there are benefits from knowledge-sharing behaviors, the enterprise would eventually choose a sharing strategy. When the incentive, penalty, cost, trust, and transformation ability coefficients are changing, the powerful knowledge organization is more sensitive to parameter changing than the organization at the weak knowledge position. In addition, compared with the powerful knowledge organization group, the no sharing strategy of the weak knowledge enterprise group converges faster to 0 ; that is, the weak knowledge enterprise group will choose the 
knowledge-sharing strategy earlier because it can get more knowledge and information in the knowledgesharing network, and it is more willing to participate in the knowledge-sharing strategy.

(2) Second, the effects of incentive and penalty on the two organization groups are quite different. The result shows that the implementation of incentive and penalty has significantly different effects on the change range and convergence speed of strategy selection of the two enterprise groups. Incentive measures can increase the knowledgesharing benefits and effectively guide and promote the powerful knowledge enterprise groups toward sharing strategies. At the same time, the increasing penalty has a pronounced restraining effect on the opportunistic behavior of weak knowledge power enterprise groups and promotes them to choose knowledge-sharing strategies. Therefore, the core enterprise in the PPP supply chain should formulate a reasonable incentive mechanism to reduce the sharing cost and improve the incentive effect, so as to ensure the reasonable interests of the knowledge-sharing enterprises.

(3) Thirdly, the proportion of enterprises choosing no sharing strategy can be reduced with the improvement of knowledge-sharing ability. Moreover, enterprises in different knowledge positions have different sensitivities with knowledge-sharing ability. When the cost coefficient is reduced, the change range of strategy selection of the powerful knowledge enterprise group would be at the most extensive level. Furthermore, the higher trust coefficient can promote the strong knowledge power enterprise to choose the sharing strategy more quickly. When the transformation ability is improved, the weak knowledge power enterprise groups will evolve to the sharing strategy faster than the powerful knowledge organization. It can be seen that increasing the mutual trust coefficient, reducing the sharing cost, and improving the enterprise's transformation ability will help both sides to evolve into the sharing strategy more quickly.

This research has made three theoretical contributions. Firstly, a conceptual model of the PPP supply chain network is built. Secondly, in the complex environment, the stochastic evolutionary game model for knowledge sharing in the PPP supply chain network is constructed, and the evolution mechanism of the knowledge-sharing strategies is also presented. Finally, the sensitivity rules of the incentive, penalty, cost, trust, and transformation ability coefficients show the way for core organizations in the PPP supply chain to build a knowledge-sharing mechanism.

In order to improve the knowledge-sharing behavior of enterprises in the PPP supply chain and promote the effective transfer of knowledge in the supply chain, the following suggestions are put forward:
(1) Build the PPP supply chain knowledge-sharing platform and establish the trust mechanism between members. PPP supply chain knowledge sharing requires the establishment of a complete knowledgesharing information platform. The members can select appropriate enterprises for cooperation according to their needs to ensure the success rate of cooperation and the effective transfer of knowledge. The trust rating system of sharing members should be established. The enterprises with low trust rank should be restricted from entering the knowledgesharing platform to reduce the risk of knowledge leakage. The enterprises will actively choose to cooperate with higher trust levels to promote corporate trust culture and system in the PPP supply chain.

(2) The core players should strengthen the supervision of supply chain members and establish a sound incentive mechanism. The appropriate rewards and compensations should be provided to the enterprises that actively share knowledge, which would motivate them to continue to maintain knowledge-sharing behavior. For enterprises with opportunistic behaviors, necessary punitive measures should be taken to increase their willingness to share knowledge. A perfect incentive mechanism is helpful to protect the interests of sharers, regulate the behavior of speculators, and create a right knowledge-sharing environment.

(3) Enterprises should strengthen learning and pay attention to improving their sharing ability. Through continuous learning, accumulation, and innovation, we can bridge the status inequality and knowledge gap between sharing enterprises. It can enable enterprises to gain more benefits from the sharing process by lowering the sharing cost and improving the ability to transform knowledge. If the rate of transformation and willingness to share knowledge is continually increasing, the evolution of a shared strategy would be faster.

There are still some limitations to this study. Firstly, the current study just focuses on the stability analysis for the stochastic evolutionary game model. However, unstable states are also important, and they should be the next research direction. Secondly, the influence of knowledge stock, risk coefficient, and other factors on knowledge-sharing income of the supply chain can also be further analyzed.

\section{Data Availability}

The data used to support the findings of this study are available from the corresponding author upon request.

\section{Conflicts of Interest}

The authors declare that there are no conflicts of interest regarding the publication of this paper. 


\section{Acknowledgments}

The authors acknowledge with gratitude the MOE (Ministry of Education in China) Project of Humanities and Social Sciences (no. 19YJC630078), National Key R\&D Program of China (no. 2018YFC0406905), Youth Talents Teachers Scheme of Henan Province Universities (no. 2018GGJS080), the National Natural Science Foundation of China (nos. 71974056 and 71302191), the Foundation for Distinguished Young Talents in Higher Education of Henan (Humanities and Social Sciences), China (no. 2017-cxrc-023), the China Scholarship Council (no. 201908410388), and 2018 Henan Province Water Conservancy Science and Technology Project (no. GG201828). This study would not have been possible without their financial support.

\section{References}

[1] A. N. Chowdhury, P. H. Chen, and R. L. K. Tiong, "Analysing the structure of public-private partnership projects using network theory," Construction Management and Economics, vol. 29, no. 3, pp. 247-260, 2011.

[2] M. Christopher, "Logistics and supply chain management: strategies for reducing costs and improving services," Journal of the Operational Research Society, vol. 45, no. 11, p. 1341, 1994.

[3] S. Pryke, Construction Supply Chain Management: Concepts and Case Studies, Wiley-Blackwell, Oxford, UK, 2009.

[4] P. J. Singh and D. Power, "Innovative knowledge sharing, supply chain integration and firm performance of Australian manufacturing firms," International Journal of Production Research, vol. 52, no. 21, pp. 6416-6433, 2014.

[5] J. Egan, Rethinking Construction, Department of Environment Transport and the Regions. HMSO, London, UK, 1998.

[6] J. Bennett and S. Jayes, Trusting the Team: The Best Practice Guide to Partnering in Construction, Thomas Telford, London, UK, 1995.

[7] H. Robinson, P. Carrillo, C. J. Anumba, and M. Patel, Governance and Knowledge Management for Public-Private Partnerships, John Wiley \& Sons, Oxford, UK, 2009.

[8] P. E. Eriksson, "Improving construction supply chain collaboration and performance: a lean construction pilot project," Supply Chain Management-An International Journal, vol. 15, no. 5, pp. 394-403, 2010.

[9] R. Vrijhoef and L. Koskela, "The four roles of supply chain management in construction," European Journal of Purchasing \& Supply Management, vol. 6, no. 3-4, pp. 169-178, 2000.

[10] A. Akintoye and J. Main, "Collaborative relationships in construction: the UK contractors' perception," Engineering, Construction and Architectural Management, vol. 14, no. 6, pp. 597-617, 2007.

[11] L.-E. Gadde and A. Dubois, "Partnering in the construction industry-problems and opportunities," Journal of Purchasing and Supply Management, vol. 16, no. 4, pp. 254-263, 2010.

[12] N. Alderman and C. Ivory, "Partnering in major contracts: paradox and metaphor," International Journal of Project Management, vol. 25, no. 4, pp. 386-393, 2007.

[13] D. Simchi-Levi, P. Kaminsky, E. Simchi-Levi, and R. Shankar, Designing and Managing the Supply Chain: Concepts, Strategies and Case Studies, Tata McGraw-Hill Education, New York, NY, USA, 2008.
[14] J. U. D. Hatmoko and S. Scott, "Simulating the impact of supply chain management practice on the performance of medium-sized building projects," Construction Management and Economics, vol. 28, no. 1, pp. 35-49, 2010.

[15] P. Behera, R. P. Mohanty, and A. Prakash, "Understanding construction supply chain management," Production Planning \& Control, vol. 26, no. 16, pp. 1332-1350, 2015.

[16] X. Xue, Y. Wang, Q. Shen, and X. Yu, "Coordination mechanisms for construction supply chain management in the Internet environment," International Journal of Project Management, vol. 25, no. 2, pp. 150-157, 2007.

[17] H. Albaloushi and M. Skitmore, "Supply chain management in the UAE construction industry," International Journal of Construction Management, vol. 8, no. 1, pp. 53-71, 2008.

[18] D. Aloini, R. Dulmin, V. Mininno, and S. Ponticelli, "Supply chain management: a review of implementation risks in the construction industry," Business Process Management Journal, vol. 18, no. 5, pp. 735-761, 2012.

[19] A. Cox and P. Ireland, "Managing construction supply chains: the common sense approach," Engineering Construction and Architectural Management, vol. 9, no. 5-6, pp. 409-418, 2002.

[20] A. Akintoye, G. McIntosh, and E. Fitzgerald, "A survey of supply chain collaboration and management in the UK construction industry," European Journal of Purchasing \& Supply Management, vol. 6, no. 3-4, pp. 159-168, 2000.

[21] C. Hao, Q. Du, Y. Huang, L. Shao, and Y. Yan, "Evolutionary game analysis on knowledge-sharing behavior in the construction supply chain," Sustainability, vol. 11, no. 19, p. 5319, 2019.

[22] B. K. Baiden, A. D. F. Price, and A. R. J. Dainty, "The extent of team integration within construction projects," International Journal of Project Management, vol. 24, no. 1, pp. 13-23, 2006.

[23] D. Nicolini, R. Holti, and M. Smalley, "Integrating project activities: the theory and practice of managing the supply chain through clusters," Construction Management and Economics, vol. 19, no. 1, pp. 37-47, 2001.

[24] G. Briscoe and A. Dainty, "Construction supply chain integration: an elusive goal?" Supply Chain Management: An International Journal, vol. 10, no. 4, pp. 319-326, 2005.

[25] X. Ruan, E. G. Ochieng, A. D. F. Price, and C. O. Egbu, "Knowledge integration process in construction projects: a social network analysis approach to compare competitive and collaborative working," Construction Management and Economics, vol. 30, no. 1, pp. 5-19, 2012.

[26] A. Styhre and P. Gluch, "Managing knowledge in platforms: boundary objects and stocks and flows of knowledge," Construction Management and Economics, vol. 28, no. 6, pp. 589-599, 2010.

[27] Q. Wang and Q. Shi, “The incentive mechanism of knowledge sharing in the industrial construction supply chain based on a supervisory mechanism," Engineering, Construction and Architectural Management, vol. 26, no. 6, pp. 989-1003, 2019.

[28] E. J. Boyer, "Identifying a knowledge management approach for public-private partnerships," Public Performance \& Management Review, vol. 40, no. 1, pp. 158-180, 2016.

[29] M. Duryan and H. Smyth, "Service design and knowledge management in the construction supply chain for an infrastructure programme," Built Environment Project and Asset Management, vol. 9, no. 1, pp. 118-137, 2019.

[30] S. Newell, "Managing knowledge and managing knowledge work: what we know and what the future holds," Journal of Information Technology, vol. 30, no. 1, pp. 1-17, 2015.

[31] S. Shang, "A comprehensive relational model of factors influencing knowledge sharing: an empirical study," 
International Journal of Knowledge Management (IJKM), vol. 10, no. 1, pp. 1-25, 2014.

[32] C.-M. Chang, M.-H. Hsu, and Y.-J. Lee, "Factors influencing knowledge-sharing behavior in virtual communities: a longitudinal investigation," Information Systems Management, vol. 32, no. 4, pp. 331-340, 2015.

[33] M. S. Rahman, N. Mat Daud, H. Hassan, and A. M. Osmangani, "Effects of workplace spirituality and trust mediated by perceived risk towards knowledge sharing behaviour," VINE Journal of Information and Knowledge Management Systems, vol. 46, no. 4, pp. 450-468, 2016.

[34] D. Gann, "Putting academic ideas into practice: technological progress and the absorptive capacity of construction organizations," Construction Management and Economics, vol. 19, no. 3, pp. 321-330, 2001.

[35] M. Saini, M. Arif, and D. J. Kulonda, "Challenges to transferring and sharing of tacit knowledge within a construction supply chain," Construction Innovation, vol. 19, no. 1, pp. 15-33, 2019.

[36] A. Y. Ni, "The risk-averting game of transport public-private partnership," Public Performance \& Management Review, vol. 36, no. 2, pp. 253-274, 2012.

[37] G. A. Hodge and K. Coghill, "Accountability in the privatized state," Governance, vol. 20, no. 4, pp. 675-702, 2007.

[38] M. Gross and M. Garvin, "Structuring PPP toll-road contracts to achieve public pricing objectives," Engineering Project Organization Journal, vol. 1, no. 2, pp. 143-156, 2011.

[39] H. S. Robinson, M. Carrillo, C. J. Anumba, and A. M. AlGhassani, "Linking knowledge management strategy to business performance in construction organisations," in Proceedings of the 17th Annual ARCOM Conference, Salford, UK, September 2001.

[40] P. M. Carrillo, H. S. Robinson, C. J. Anumba, and N. M. Bouchlaghem, "A knowledge transfer framework: the PFI context," Construction Management and Economics, vol. 24, no. 10, pp. 1045-1056, 2006.

[41] J. Newton, "Evolutionary game theory: a renaissance," Games, vol. 9, no. 2, p. 31, 2018.

[42] D. Easley and J. Kleinberg, Networks, Crowds, and Markets, Vol. 8, Cambridge University Press, Cambridge, UK, 2010.

[43] T. L. Vincent and J. S. Brown, Evolutionary Game Theory, Natural Selection, and Darwinian Dynamics, Cambridge University Press, Cambridge, UK, 2005.

[44] R. Fan and J. Zhen, "Analysis of evolutionary game of cooperative competition mechanism in supply chain enterprises," Journal of Advanced Oxidation Technologies, vol. 21, no. 2, 2018.

[45] Y. Tian, K. Govindan, and Q. Zhu, “A system dynamics model based on evolutionary game theory for green supply chain management diffusion among Chinese manufacturers," Journal of Cleaner Production, vol. 80, pp. 96-105, 2014.

[46] S. Babu and U. Mohan, "An integrated approach to evaluating sustainability in supply chains using evolutionary game theory," Computers \& Operations Research, vol. 89, pp. 269283, 2018.

[47] J. Xu, J. Cao, Y. Wang, X. Shi, and J. Zeng, "Evolutionary game on government regulation and green supply chain decisionmaking," Energies, vol. 13, no. 3, 2020.

[48] Q. Li and Y. Kang, "Knowledge sharing willingness and leakage risk: an evolutional game model," Sustainability, vol. 11, no. 3, 2019.

[49] P. Ritala, H. Olander, S. Michailova, and K. Husted, "Knowledge sharing, knowledge leaking and relative innovation performance: an empirical study," Technovation, vol. 35, pp. 22-31, 2015.

[50] Y. Xu, B. Hu, and R. Qian, "Analysis on stability of strategic alliances based on stochastic evolutionary game including simulations," Systems Engineering-Theory \& Practice, vol. 31, no. 5, pp. 920-926, 2011.

[51] J. Huang and H. Zhang, "A method for selecting defense strategies based on stochastic evolutionary game model," Acta Electronica Sinica, vol. 46, no. 9, pp. 2222-2228, 2018.

[52] D. J. Higham, "An algorithmic introduction to numerical simulation of stochastic differential equations," SIAM Review, vol. 43, no. 3, pp. 525-546, 2001.

[53] S. Hu, Stochastic Differential Equation, Science Press, Beijing, China, 2008.

[54] C. T. H. Baker and E. Buckwar, "Exponential stability in $p$-th mean of solutions, and of convergent Euler-type solutions, of stochastic delay differential equations," Journal of Computational \& Applied Mathematics, vol. 184, no. 2, pp. 404-427, 2004.

[55] A. Rai, R. Patnayakuni, and N. Seth, "Firm performance impacts of digitally enabled supply chain integration capabilities," Mis Quarterly, vol. 30, no. 2, pp. 225-246, 2006.

[56] R. B. Handfield and C. Bechtel, "The role of trust and relationship structure in improving supply chain responsiveness," Industrial Marketing Management, vol. 31, no. 4, pp. 367-382, 2002.

[57] J. Pfeffer and G. R. Salancik, The External Control of Organizations: A Resource Dependence Perspective, Stanford University Press, Palo Alto, CA, USA, 2003.

[58] Y. J. Li, N. He, H. M. Li, Z. Q. Liu, and J. Y. Qi, "Influencing factors on inter-organizational trust asymmetry behavior in construction projects Evidence from China," Engineering Construction and Architectural Management, p. 24.

[59] G. Aerts and E. Haezendonck, "Development and application of an inter-organizational PPP knowledge transfer effectiveness model for knowledge sourced in public sector organizations," American Journal of Industrial and Business Management, vol. 7, no. 5, p. 671, 2017.

[60] M. E. Jennex, S. Smolnik, and D. Croasdell, "Towards defining knowledge management success," in Proceedings of the 40th Annual Hawaii International Conference on System Sciences (HICSS'07), January 2007. 